\title{
Metabolism of thyroid hormones in cultured cardiac fibroblasts of neonatal rats
}

\author{
S M van der Heide, T J Visser ${ }^{1}$, M E Everts and P H M Klaren
}

Department of Veterinary Anatomy and Physiology, Faculty of Veterinary Medicine, Utrecht University, PO Box 80157, 3508 TD Utrecht, The Netherlands

${ }^{1}$ Department of Internal Medicine, Erasmus University Medical School, 3000 DR Rotterdam, The Netherlands

(Requests for offprints should be addressed to P H M Klaren; Email: p.klaren@vet.uu.nl)

\begin{abstract}
We have investigated the potential role of fibroblasts in local thyroid hormone metabolism in neonatal rat heart. Incubation of cardiac fibroblasts with thyroxine (T4) or $3,5,3^{\prime}$-tri-iodothyronine (T3) resulted in the appearance of water-soluble metabolites, whereas incubation of cardiomyocytes under the same conditions did not or did so to a much lesser extent. Time-course studies showed that production is already evident after $1-5 \mathrm{~h}$ of exposure and that the process equilibrates after 24-48 h. Analysis of the products revealed both the T4 and the T3 metabolites to be glucuronides. These results were corroborated
\end{abstract}

by the detection of uridine diphosphate (UDP)glucuronyltransferase activity in cardiac fibroblasts. We found no indication for outer ring deiodination in fibroblasts, cardiomyocytes or heart homogenates.

From these results we have concluded that cardiac fibroblasts, but not cardiomyocytes, are able to glucuronidate T4 and T3 and secrete the conjugates. This could play a role in local metabolism, e.g. to protect the heart tissue from high levels of thyroid hormones.

Journal of Endocrinology (2002) 174, 111-119

\section{Introduction}

The main secretory product of the thyroid gland is thyroxine (T4). Deiodination of T4 to form 3,5,3'-triiodothyronine (T3) is an important metabolic pathway, as are glucuronidation and sulfation pathways to form glucuronated and sulfated thyroid hormone conjugates respectively. Both conjugates have an increased water solubility, facilitating urinary and biliary excretion. Thyroid hormone glucuronides, which are excreted in bile, are hydrolyzed by bacterial glucuronidases in the gut and are partly reabsorbed as native thyroid hormones in the enterohepatic cycle (Visser 1996).

A major target organ for thyroid hormones is the heart. The genomic actions of T3 are well described, and it is through regulation of the transcription of genes coding for e.g. sarcoplasmic reticulum $\mathrm{Ca}^{2+}$-ATPase, subunits of the plasma membrane sodium pump $\left(\mathrm{Na}^{+} / \mathrm{K}^{+}\right)$-ATPase, and $\alpha-$ and $\beta$-isoforms of the contractile protein myosin heavy chain (Kessler-Icekson 1988, Rohrer \& Dillmann 1988, Dillmann 1990, Horowitz et al. 1990, Muller et al. 1997) that T3 affects cardiac inotropic and chronotropic performance. It is not yet clear whether this occurs because of uptake of T3 from the blood or uptake of T4 that is locally converted to T3 in the heart (van Doorn et al. 1985).

On a protein basis, cardiomyocytes compose about $90 \%$ of the heart. Measured by cell numbers, however, the fibroblast is the most abundant cell type in the heart, constituting an estimated two-thirds of the total cardiac cell population (Nair et al. 1968, Agocha \& Eghbali-Webb 1997). The thyroid status of an animal not only affects cardiomyocyte function, but also that of cardiac fibroblasts. Rats in which ventricular hypertrophy is induced by injections of T4 have a decreased expression of collagen type-I and an increased collagen turnover in ventricular tissue (Klein et al. 1996). The inhibitory effect of T4 on cardiac collagen synthesis has been observed in rat, mouse and dog (Edgren et al. 1976, Bonnin et al. 1983, Yao \& Eghbali 1992a,b, Kim et al. 1996, Klein et al. 1996), and it has been postulated that this negatively affects the supporting properties of the myocardial connective tissue (Edgren et al. 1976). Fibroblasts from human skin biopsies express a thyroid hormone receptor (Mixson et al. 1993), and it is possible that, besides the well-investigated collagen genes, novel thyroid hormone-responsive genes will be identified in (cardiac) fibroblasts. Indeed, the recently discovered ZAKI-4 gene, with an as yet unknown function, was identified in fibroblasts and found to be transcribed in heart and several other organs (Miyazaki et al. 1996a,b).

It has been shown that cultured fibroblasts possess a saturable and energy-dependent T4 uptake mechanism with a $K_{\mathrm{m}}$ value 15 times lower than that for T3 (Docter et al. 1987). Other studies, performed with skin and 
cardiac fibroblasts, confirm the observations of T4 and T3 uptake and also provide indications for a temperatureand verapamil-sensitive thyroid hormone extrusion mechanism in these cells, possibly mediated through P-glycoprotein, a member of the multi-drug resistance protein family (Ribeiro et al. 1996, Benvenga \& Robbins 1998). Investigations in other organs have shown that fibroblasts play a local, paracrine role for subepithelial fibroblasts in the intestine (Berschneider \& Powell 1992, Kandil et al. 1994).

Based on these experimental data we propose the hypothesis that fibroblasts are equipped to fulfil a potential role in local thyroid hormone metabolism in the heart. We investigated this hypothesis in cultured fibroblasts and myocytes from neonatal rats. After exposure to T4 or T3 the iodothyronine metabolites in the culture medium were determined using Sephadex LH-20 chromatography.

\section{Materials and Methods}

\section{Materials}

All reagents used for cell isolation and cell culture were obtained from Life Technologies BV (Breda, The Netherlands), with the exception of trypsin (Boehringer, Mannheim, Germany). Polystyrene 24-well culture dishes were from Corning Costar Europe (Badhoevedorp, The Netherlands). Iodothyronines (T3, 3,3',5'-triiodothyronine (rT3) and T4), 6-n-propyl-2-thiouracil (PTU), $\quad \beta$-D-glucuronidase, DL-dithiothreitol (DTT), uridine $5{ }^{\prime}$-diphosphoglucuronic acid (UDPGA), $p$ nitrophenol $(p \mathrm{NP})$ and bovine serum albumin (BSA) (fraction V) were purchased from Sigma Chemical Co. (St Louis, MO, USA). $\left[{ }^{125} \mathrm{I}\right] \mathrm{T} 3(81 \cdot 4 \mathrm{TBq} / \mathrm{mmol}),\left[{ }^{125} \mathrm{I}\right] \mathrm{rT} 3$ $(29.9 \mathrm{TBq} / \mathrm{mmol})$ and $\left[{ }^{125} \mathrm{I}\right] \mathrm{T} 4(4.3 \mathrm{TBq} / \mathrm{mmol})$ were obtained from NEN Life Science Products, Inc. (Boston, MA, USA). Sephadex LH-20 was purchased from Amersham Pharmacia Biotech Benelux (Roosendaal, The Netherlands). All other chemicals were analytical grade and obtained from commercial supplies.

\section{Animals}

Three-day-old Wistar rats were obtained from laboratory stock (Utrecht University, The Netherlands). They were killed by decapitation and hearts were quickly dissected and processed as described below. All experiments were approved by the local ethical committee.

\section{Cell culture}

Primary cultures of neonatal rat cardiac fibroblasts and cardiomyocytes were prepared using a trypsin digestion method as described previously (Everts et al. 1996). Hearts were digested using trypsin to obtain a cell suspension. Cardiac fibroblasts were obtained by preplating the cell suspension for $2 \mathrm{~h}$ in culture flasks and cultured at $37^{\circ} \mathrm{C}$ in a $5 \% \mathrm{CO}_{2}$ atmosphere in 4:1 (w/w) Dulbecco's modified Eagle's medium/medium 199 supplemented with 5\% horse serum, $5 \%$ fetal calf serum and 2\% penicillin/ streptomycin. Cardiomyocytes were separated from the fibroblasts by aspiration of the culture medium and seeded into 24-well culture dishes at a density of $1.0 \times 10^{6}$ cells/well. Two days after isolation the medium of both fibroblast and myocyte cultures was replaced by fresh medium. Fibroblasts were grown for 6 days, after which they were harvested with $0 \cdot 25 \%$ trypsin in $\mathrm{Ca}^{2+}$-free buffer and seeded into 24-well culture dishes at a density of $1 \cdot 0 \times 10^{6}$ cells $/$ well.

\section{Deiodinase assays}

D1 After 6 days of culture, culture medium was removed and fibroblasts were quickly washed with $2 \times 2 \mathrm{ml}$ $150 \mathrm{mM} \mathrm{KCl}$. Cells were harvested by trypsinization, suspended in $1 \mathrm{ml} 150 \mathrm{mM} \mathrm{KCl}$ and rinsed three times in $100 \mu \mathrm{l} 150 \mathrm{mM} \mathrm{KCl}$. Cells were disrupted in three cycles of snap freezing in liquid nitrogen and rapid thawing at $37^{\circ} \mathrm{C}$. Trypan blue exclusion tests showed that virtually $100 \%$ was disrupted. Cellular protein content was measured according to Lowry et al. (1951), using BSA as a reference. Cells were incubated for $15 \mathrm{~min}$ at $37^{\circ} \mathrm{C}$ with $1 \mu \mathrm{M}$ rT3 and tracer $\left(\left[{ }^{125} \mathrm{I}\right] \mathrm{rT} 3,10^{6}\right.$ c.p.m. $\left./ \mathrm{ml}\right)$ in incubation medium (100 mM phosphate buffer, 2 mM EDTA, $10 \mathrm{mM}$ DTT) in the presence or absence of $100 \mu \mathrm{M}$ PTU. The reaction was quenched by adding $100 \mu \mathrm{l} \%$ ice-cold BSA followed by $500 \mu \mathrm{l} 10 \%$ trichloroacetic acid for deproteinization. Samples were centrifuged $(15 \mathrm{~min}$ at $4{ }^{\circ} \mathrm{C}, 1500 \mathrm{~g}$ ) and $500 \mu \mathrm{l}$ of the supernatant was acidified with $500 \mu \mathrm{l} 1.0 \mathrm{M} \mathrm{HCl}$. Liberated iodide was analyzed by Sephadex LH-20 column chromatography as described below, collecting the first three $1 \mathrm{ml} 0 \cdot 1 \mathrm{M} \mathrm{HCl}$ eluates. A crude rat liver homogenate served as a positive control. The specific D1 activity was thus measured as the PTUsensitive outer ring deiodination of rT3.

D2 The methods were the same as in our D1 assays, using $0.5 \mu \mathrm{M} \mathrm{T} 4$ as a substrate and $20 \mathrm{mM}$ DTT. PTU was omitted from the incubation medium.

\section{Exposure of fibroblasts to thyroid hormones}

Fibroblasts grown in a 24-well culture dish were washed with $1 \mathrm{ml}$ saline, and then incubated in $1.5 \mathrm{ml}$ culture medium to which $100 \mathrm{nM}$ T3 or $100 \mathrm{nM}$ T4 was added (using $10^{6}$ c.p.m./ml $\left[{ }^{125} \mathrm{I}\right] \mathrm{T} 3$ or $\left[{ }^{125} \mathrm{I}\right] \mathrm{T} 4$ respectively as tracer). This was done to prevent substrate depletion during the 2-day incubation period. ${ }^{125}$ I-Labeled iodothyronines were purified on Sephadex LH-20 before use. Cells were incubated at $37^{\circ} \mathrm{C}$ in a $5 \% \mathrm{CO}_{2}$ atmosphere, and $500 \mu \mathrm{l}$ samples of the incubation medium were taken 
at regular time-intervals. Iodothyronine metabolites were resolved by Sephadex LH-20 column chromatography as described below.

\section{Analysis of thyroid hormone metabolites}

Acid hydrolysis Water fractions from Sephadex LH-20 columns were pooled and evaporated to dryness under a stream of $\mathrm{N}_{2}$. The residue was dissolved in $2 \mathrm{ml} 1.0 \mathrm{M}$ $\mathrm{HCl}$ and divided into two equal aliquots. One aliquot was incubated at $80^{\circ} \mathrm{C}$ for $1 \mathrm{~h}$, the other remained on ice and served as a control.

$\boldsymbol{\beta}$-Glucuronidase digestion Water fractions were collected and evaporated to dryness as described above. The residue was dissolved in $2 \mathrm{ml} 50 \mathrm{mM}$ phosphate-buffered saline, $\mathrm{pH} 6 \cdot 8$, and divided into two equal aliquots. To one aliquot $50 \mu \mathrm{g} \beta$-D-glucuronidase was added, the other received vehicle only, and both were incubated at $37^{\circ} \mathrm{C}$ overnight.

The effects of both acid hydrolysis and the $\beta$-glucuronidase digestion were assessed by Sephadex LH-20 column chromatography as described below.

\section{Sephadex LH-20 column chromatography}

Columns consisted of Sephadex LH-20 (10\%, w/v) with a $1 \mathrm{ml}$ bed volume in a glass pipette and were equilibrated with $3 \times 1 \mathrm{ml} \mathrm{0 \cdot 1} \mathrm{M} \mathrm{HCl}$ before use. For the post-analysis following acid hydrolysis and $\beta$-glucuronidase digestion treatments, a bed volume of $2.5 \mathrm{ml}$ was used. Samples were acidified with one sample volume $1.0 \mathrm{M} \mathrm{HCl}$ before adding to the column. Chromatography was performed according to Mol \& Visser (1985), collecting the reaction products and metabolites, i.e. iodide, water-soluble conjugates and native hormones in $3 \times 1 \mathrm{ml} 0.1 \mathrm{M} \mathrm{HCl}$, $8 \times 1 \mathrm{ml} \mathrm{H}_{2} \mathrm{O}$ and $3 \times 1 \mathrm{ml} 0.5 \mathrm{M} \mathrm{NH}_{3}$ in $96 \%$ ethanol respectively. The fractions were analyzed for ${ }^{125}$ I-activity in a $\gamma$-counter (Packard Cobra II; Packard Instruments Co., Meriden, CT, USA).

\section{Synthesis of iodothyronine sulfates and glucuronides}

Sulfate synthesis T4 or $\left[{ }^{125} \mathrm{I}\right] \mathrm{T} 3$ were evaporated to complete dryness under a stream of $\mathrm{N}_{2}$ at $40{ }^{\circ} \mathrm{C}$. Chlorosulfonic acid was added to ice-cold dimethylformamide $(1: 4, v / v)$ and the mixture was added to the dry residues. The mixture was incubated for $2 \mathrm{~h}$ at $37^{\circ} \mathrm{C}$ and the reaction was stopped by adding 4 sample volumes ice-cold water. Sulfates thus synthesized separated in a single, well-defined peak on Sephadex LH-20. The final purified preparations contained virtually no contamination from free iodide or native hormone.

Glucuronide synthesis $\mathrm{T} 4$ and $\left[{ }^{125} \mathrm{I}\right] \mathrm{T} 3$ were evaporated to complete dryness under a stream of $\mathrm{N}_{2}$ at $40{ }^{\circ} \mathrm{C}$. Microsomes were used from livers of polychlorinated biphenyl-treated rats (van Birgelen et al. 1997). Mixtures of iodothyronine $(1 \mu \mathrm{M})$ and tracer $\left(10^{6}\right.$ c.p.m. $\left[{ }^{125} \mathrm{I}\right]$ iodothyronine), $5 \mathrm{mM}$ UDPGA and microsomes $(1 \mathrm{mg} / \mathrm{ml})$ in Tris- $\mathrm{HCl}\left(100 \mathrm{mM}\right.$ Tris- $\mathrm{HCl}, 10 \mathrm{mM} \mathrm{MgCl}_{2}, \mathrm{pH} 7 \cdot 8$ ) were incubated at $37^{\circ} \mathrm{C}$ for $2 \mathrm{~h}$. The reaction was stopped by adding 1 sample volume ice-cold methanol and the mixtures were centrifuged (15 min, $2200 \mathrm{~g}$ ). The supernatants were acidified with one sample volume $1 \cdot 0 \mathrm{M} \mathrm{HCl}$ before Sephadex LH-20 chromatography as described above. Glucuronides thus obtained separated in a single, well-defined peak of water eluates from Sephadex LH-20 columns. Water fractions were collected, acidified and chromatographed, using $3 \times 1 \mathrm{ml} 0 \cdot 1 \mathrm{M} \mathrm{HCl}, 1 \times 1 \mathrm{ml}$ $\mathrm{H}_{2} \mathrm{O}$ and $3 \times 1 \mathrm{ml} 0.5 \mathrm{M} \mathrm{NH}_{3}$ in $96 \%$ ethanol. Fractions $5-7$, containing purified glucuronides with virtually no contamination from free iodide or native iodothyronines, were pooled and evaporated to dryness before use in our assays.

\section{Uridine diphosphate (UDP)-glucuronyltransferase assay}

Cells were harvested and protein content was measured as described earlier. Cells, in an amount of $1 \mathrm{mg} / \mathrm{ml}$ protein, were incubated with $1 \mu \mathrm{M} p \mathrm{NP}$ in incubation medium (100 mM Tris- $\mathrm{HCl}, 5 \mathrm{mM} \mathrm{MgCl}_{2}, 0 \cdot 05 \%$ Brij56) in the presence or absence of $5 \mathrm{mM}$ UDPGA $\left(30 \mathrm{~min}\right.$ at $\left.37^{\circ} \mathrm{C}\right)$. The reaction was quenched by adding $3.8 \mathrm{ml} 0.1 \mathrm{M}$ ice-cold $\mathrm{NaOH}$ and absorbance was measured at $405 \mathrm{~nm}$.

\section{Free fraction analysis}

Free hormone fractions, from which free hormone concentrations were calculated, were measured by equilibrium dialysis as previously described (Sterling \& Brenner 1966). In culture medium containing $9 \%$ serum and $100 \mathrm{nM} \mathrm{T} 4$ or $100 \mathrm{nM} \mathrm{T3}$, the free fractions were $1 \cdot 2 \pm 0.06 \%$ and $3 \cdot 9 \pm 0 \cdot 28 \%$ (means \pm S.D. of one triplicate determination) respectively.

\section{Statistics}

All data are shown as means \pm S.E.M. unless indicated otherwise. Statistical significance was evaluated by Student's $t$-test, non-parametric Mann-Whitney test or Welch's approximate alternate $t$-test where appropriate. Significance was accepted at $P<0 \cdot 05$. The number of observations $(n)$ is shown in parentheses.

\section{Results}

We were not able to detect any outer ring deiodinating activity of either D1 or D2 in either neonatal cardiac fibroblasts or neonatal cardiomyocytes (data not shown). Figures $1 \mathrm{~A}$ and $2 \mathrm{~A}$ show that, upon 48 -h exposure to $100 \mathrm{nM}$ T4 and $100 \mathrm{nM}$ T3 respectively, cardiac fibroblasts secreted a water-soluble $\left[{ }^{125} \mathrm{I}\right]$ metabolite in their 

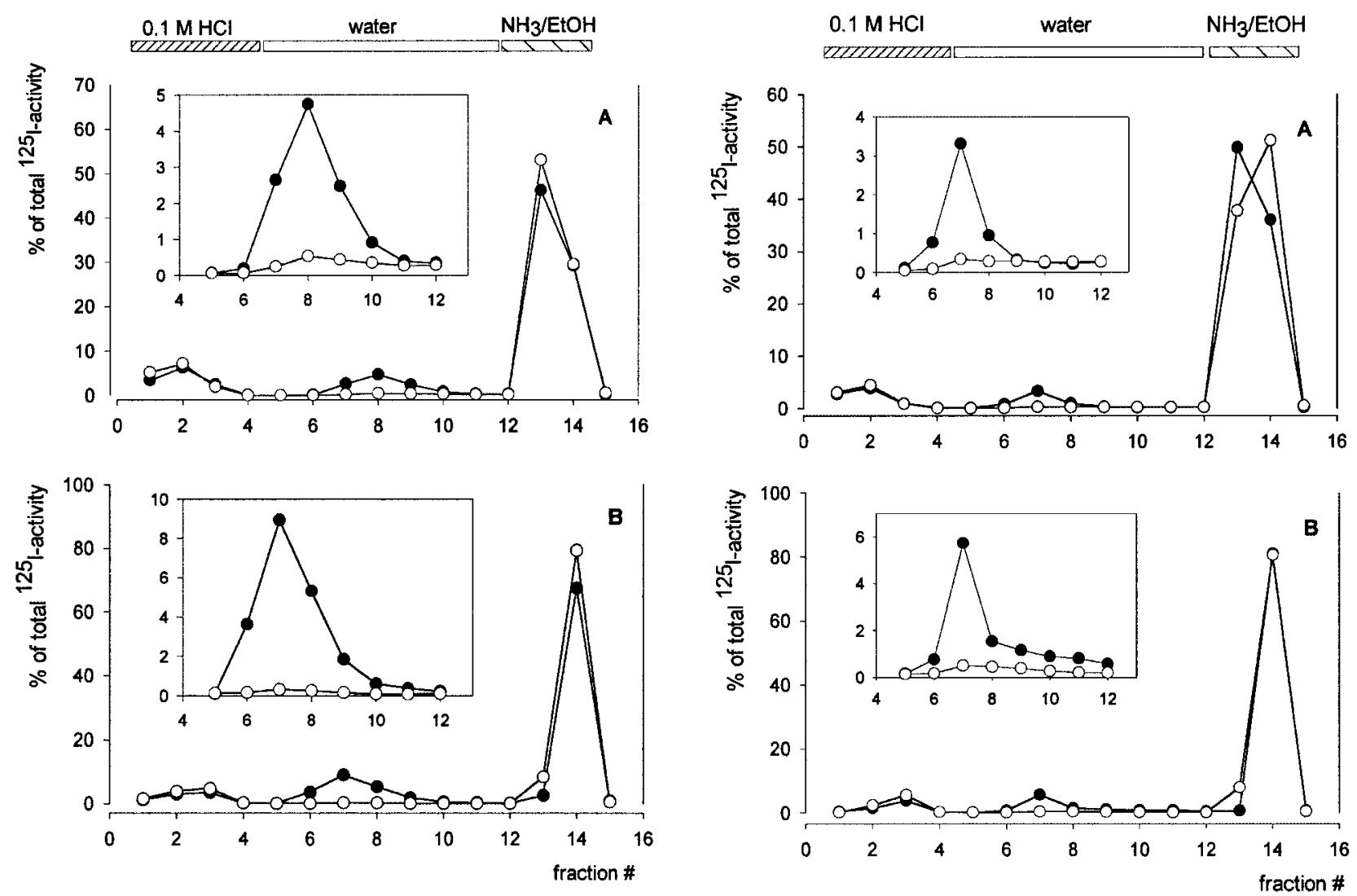

Figure 1 (A) Profile of Sephadex LH-20 elution of thyroid hormone metabolites produced by cardiac fibroblasts $(-)$ and cardiomyocytes $(\bigcirc)$ exposed to $100 \mathrm{nM} \mathrm{T4}$ with $9 \%$ serum at $t=48 \mathrm{~h}$ (typical result for 12 experiments). The inserts in $(\mathrm{A})$ and (B) show the relevant water fractions in detail. (B) Profile of Sephadex LH-20 eluates of thyroid hormone metabolites produced by cardiac fibroblasts $(\mathbf{0})$ exposed to $100 \mathrm{nM}$ T4 without serum at $t=48 \mathrm{~h}$ (typical result for 12 experiments). Wells without cells (○) served as a control.

culture medium, whereas cardiomyocytes did not. No increase in ${ }^{125}$ I-activity in the $\mathrm{HCl}$ eluates, containing free iodide, was found, indicating that no appreciable outer ring deiodination of thyroid hormones occurred, thus corroborating the negative results from our deiodinase assays. Figures $1 \mathrm{~B}$ and $2 \mathrm{~B}$ show that, upon $48-\mathrm{h}$ exposure to $100 \mathrm{nM} \mathrm{T4}$ and $100 \mathrm{nM}$ T3 respectively without serum, the water-soluble $\left[{ }^{125} \mathrm{I}\right]$ metabolite fraction secreted by cardiac fibroblasts was almost twice the amount of that found in the presence of serum, indicating a dependence on free hormone concentration.

Figure 3 shows time-courses of water-soluble iodothyronine metabolite accumulation in culture media. The production of the water-soluble T4 metabolites by cardiac fibroblasts was already measurable at our first 1-h timepoint and increased further in time (Fig. 3A). After $48 \mathrm{~h}$, the percentage was $2 \cdot 9 \pm 0 \cdot 7$ of the total ${ }^{125}$ I-activity in the incubation medium. Figure 3B shows the production

Figure 2 (A) Profile of Sephadex LH-20 eluates of thyroid hormone metabolites produced by cardiac fibroblasts $(\mathbf{0})$ and cardiomyocytes $(\bigcirc)$ exposed to $100 \mathrm{nM} \mathrm{T3}$ with $9 \%$ serum at $t=48 \mathrm{~h}$ (typical result for 12 experiments). The inserts in (A) and (B) show the relevant water fractions in detail. (B) Profile of Sephadex LH-20 eluates of thyroid hormone metabolites produced by cardiac fibroblasts ( ) exposed to $100 \mathrm{nM} \mathrm{T3}$ without serum at $t=48 \mathrm{~h}$ (typical result for 12 experiments). Wells without cells ( $\bigcirc)$ served as a control.

of the water-soluble T3 metabolites by cardiac fibroblasts, which was clearly present after $5 \mathrm{~h}$ of incubation. After $48 \mathrm{~h}$ the percentage was $2 \cdot 2 \pm 0 \cdot 3$ of total ${ }^{125}$ I-activity.

Analysis of the metabolites in the water-soluble fraction of the column chromatography

Having collected the water-soluble fractions containing the thyroid hormone metabolites, we investigated the characteristics of the product. Known water-soluble thyroid hormone conjugates are sulfates and glucuronides and we used the commonly employed acid hydrolysis and $\beta$-glucuronidase digestion to distinguish between them.

$\boldsymbol{\beta}$-Glucuronidase digestion $\beta$-Glucuronidase treatment resulted in a significant decrease $(P<0 \cdot 01)$ of the ${ }^{125} \mathrm{I}-$ activity in the two water-soluble fractions (Fig. 4) and a concomitant increase in the native iodothyronine fraction, 

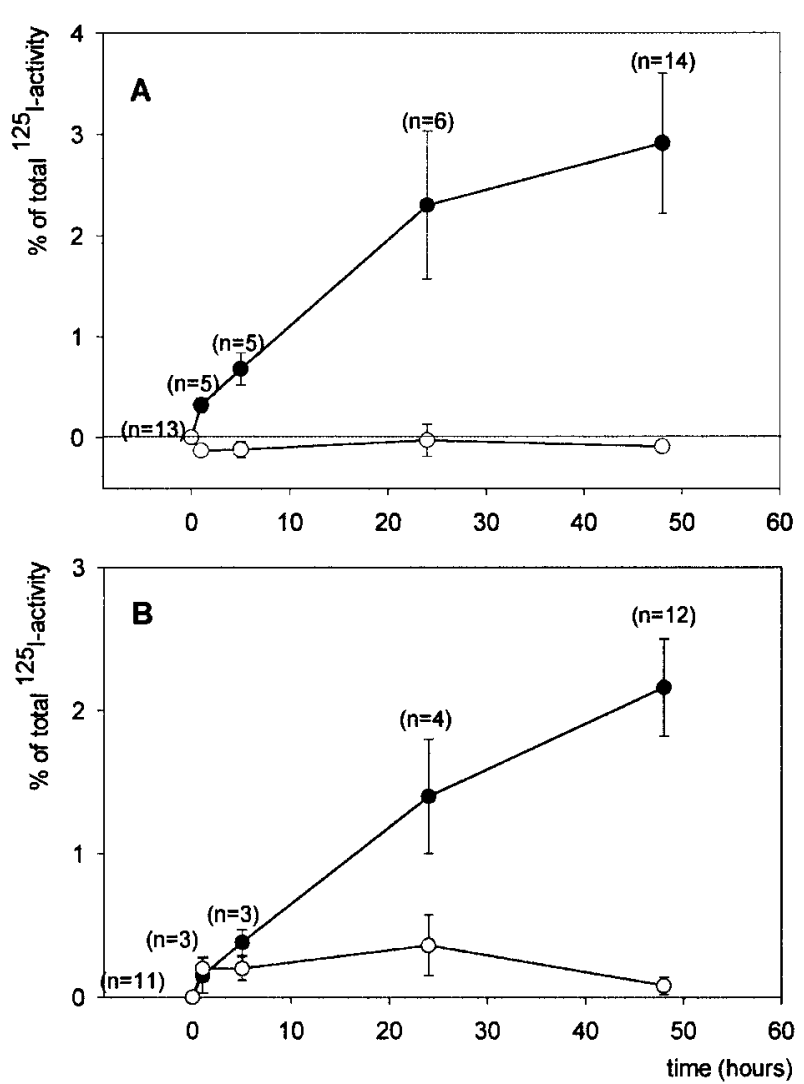

Figure 3 (A) Time-course of water-soluble metabolite produced by cardiac fibroblasts $(\mathbf{)})$ after exposure to $100 \mathrm{nM} \mathrm{T4}$. Wells without cells $(\bigcirc)$ served as a control. (B) Time-course of watersoluble metabolite produced by cardiac fibroblasts $(\mathbf{O})$ after exposure to $100 \mathrm{nM} \mathrm{T3}$. Wells without cells $(\bigcirc)$ served as a control. Values are means \pm S.E.M.

as analyzed by Sephadex column chromatography (results not shown). These results indicated that the water-soluble metabolites were glucuronides, and we therefore expected the conjugates to be insensitive to acid hydrolysis.

Acid hydrolysis Figure 5 shows that the water-soluble T3 metabolite was resistant to acid hydrolysis, which corroborated the results of the $\beta$-glucuronidase digestion. In contrast, $58 \%$ of the water-soluble T4 metabolite was sensitive to acid hydrolysis, indicating that either $\mathrm{T} 4$ sulfate is a major component of this fraction or the $\mathrm{T} 4$ metabolite is a glucuronide which is sensitive to acid hydrolysis.

We validated our analytical methods using synthetic iodothyronine sulfates and glucuronides. Figure 6A shows that, as predicted, virtually $100 \%$ of the T4 glucuronide and $\mathrm{T} 3$ glucuronide were hydrolyzed by $\beta$-glucuronidase, whereas T4 sulfate and T3 sulfate were not. Figure $6 \mathrm{~B}$ shows that $\mathrm{T} 4$ sulfate and $\mathrm{T} 3$ sulfate were sensitive to acid hydrolysis, T3 glucuronide was not and, surprisingly, that

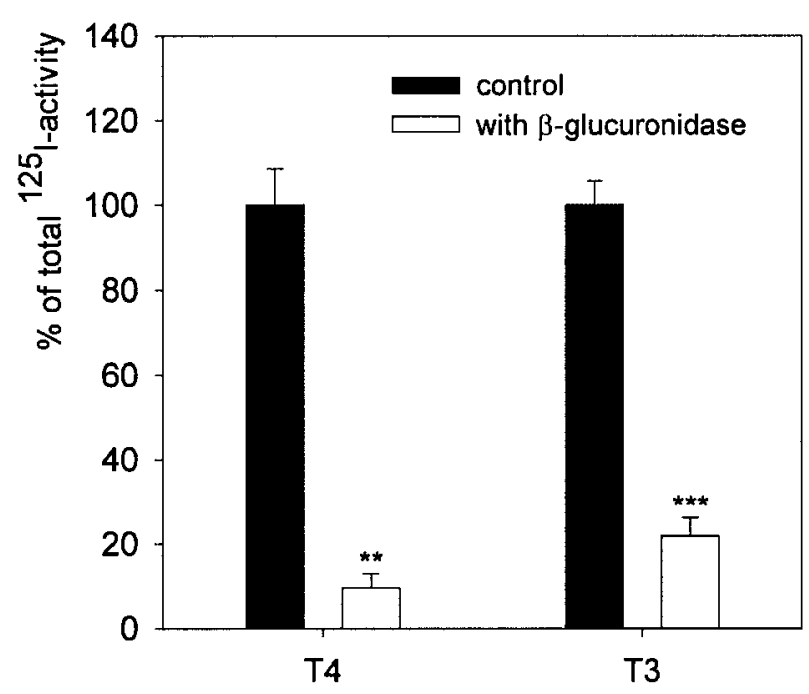

Figure 4 Analysis of the water fraction by digestion with $50 \mu \mathrm{g}$ $\beta$-glucuronidase at $37^{\circ} \mathrm{C}$ overnight of the eluate of cardiac fibroblasts (open bars) exposed to $100 \mathrm{nM} \mathrm{T4}$ and $100 \mathrm{nM}$ T3 respectively (T4, $n=2 ; \mathrm{T} 3, n=3)$. Incubation without $\beta$-glucuronidase (solid bars) served as a control. Total ${ }^{125}$ I-activity is expressed relative to control. Values are means \pm S.E.M. ${ }^{* *} P \leq 0 \cdot 01,{ }^{* *} P \leq 0 \cdot 001$.

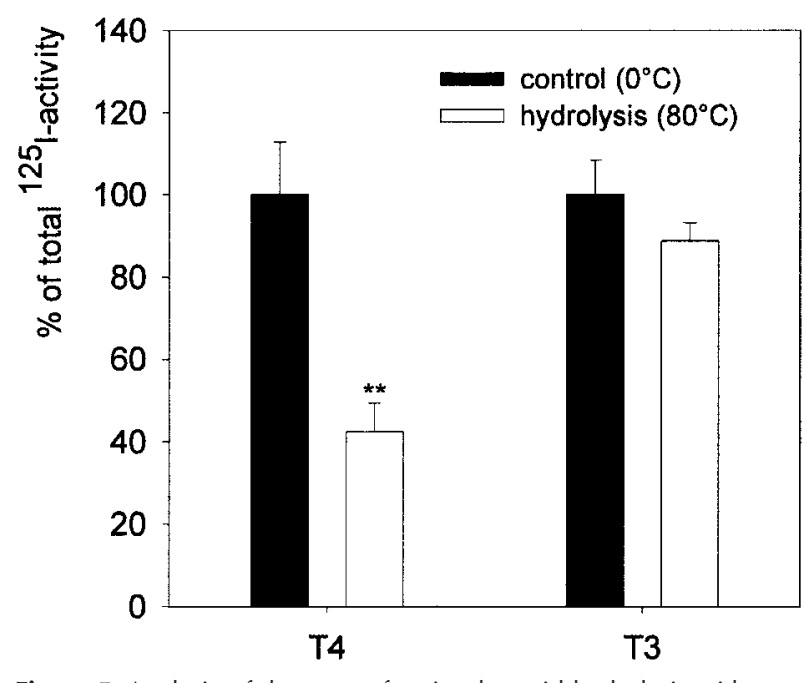

Figure 5 Analysis of the water fraction by acid hydrolysis with $1.0 \mathrm{M} \mathrm{HCl}$ for $1 \mathrm{~h}$ at $80^{\circ} \mathrm{C}$ of the eluate of cardiac fibroblasts (open bars) exposed to $100 \mathrm{nM} \mathrm{T4}$ and $100 \mathrm{nM}$ T3 respectively $(n=5)$. Incubation at $0{ }^{\circ} \mathrm{C}$ (solid bars) served as a control. Total ${ }^{125}$ I-activity is expressed relative to control. Values are means \pm S.E.M. ${ }^{* *} P \leq 0 \cdot 01$.

circa $40 \%$ of the synthetic T4 glucuronide was sensitive to this treatment. The pattern of these results concurred with the results of the analyses of the water-soluble fractions, which indicated that (1) T4 glucuronide is sensitive to acid hydrolysis and (2) cardiac fibroblasts glucuronidate iodothyronines. 

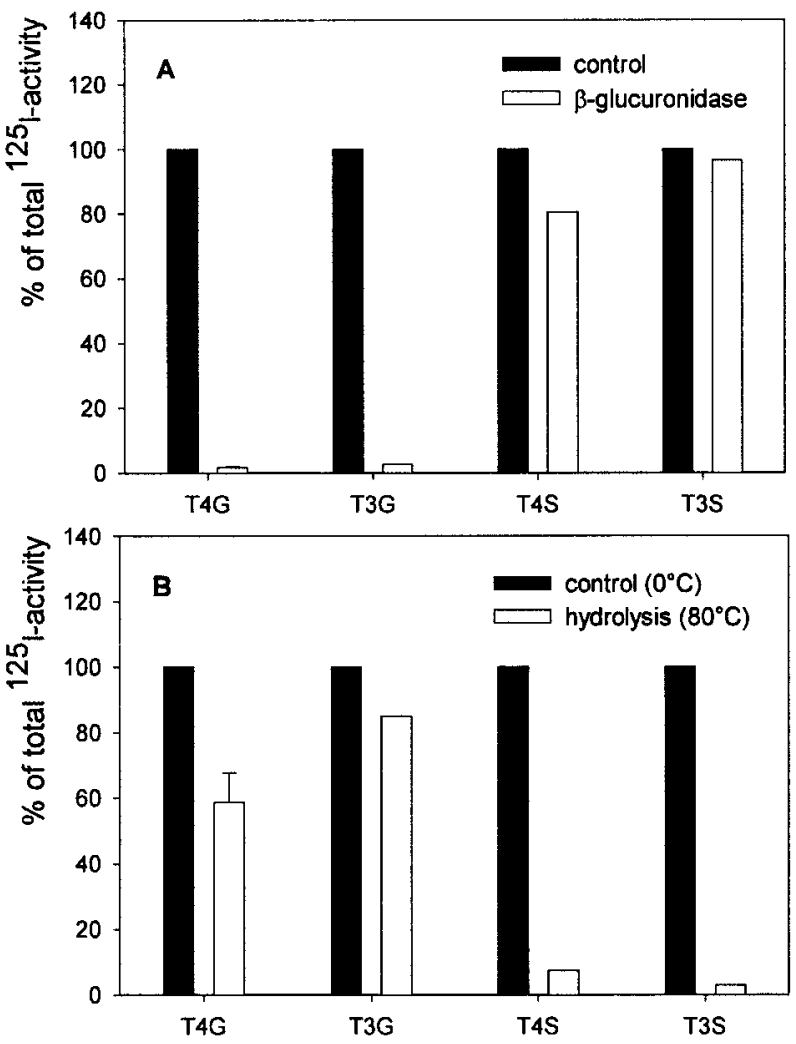

Figure 6 (A) Analysis of synthetic thyroid hormone sulfates (T4S and T3S) and thyroid hormone glucuronides (T4G and T3G) by digestion with $50 \mu \mathrm{g} \beta$-glucuronidase at $37{ }^{\circ} \mathrm{C}$ overnight (open bars) (all bars $n=1$, except for T4 glucuronide $n=2$ ). Incubation without $\beta$-glucuronidase (solid bars) served as a control. (B) Analysis of synthetic thyroid hormone sulfates and thyroid hormone glucuronides by acid hydrolysis with $1.0 \mathrm{M} \mathrm{HCl}$ for $1 \mathrm{~h}$ at $80{ }^{\circ} \mathrm{C}$ (open bars) (all bars $n=1$, except for T4 glucuronide $n=2$ ). Incubation at $0{ }^{\circ} \mathrm{C}$ (closed bars) served as a control.

Table 1 Specific UDP-glucuronyltransferase activities in different preparations from the neonatal rat (means \pm S.D.)

\begin{tabular}{ll} 
& $\begin{array}{l}\boldsymbol{p} \mathbf{N P} \\
(\mu \mathrm{mol} / \mathrm{h} \text { per mg })\end{array}$ \\
\cline { 2 - 2 } & $0 \cdot 75 \pm 0 \cdot 37$ \\
Whole liver homogenate $(n=9)$ & $0 \cdot 30 \pm 0 \cdot 32$ \\
Whole heart homogenate $(n=6)$ & $0 \cdot 90 \pm 0 \cdot 26$ \\
Cardiac fibroblasts $(n=3)$ & $0 \cdot 44 \pm 0 \cdot 39$ \\
Cardiomyocytes $(n=4)$ & \\
\hline
\end{tabular}

\section{UDP-glucuronyltransferase assay}

Table 1 shows that cardiac fibroblasts possess a phenol UDP-glucuronyltransferase activity of $0 \cdot 90 \pm 0 \cdot 26 \mu \mathrm{mol}$ $p \mathrm{NP} / \mathrm{h}$ per mg. Compared with cardiomyocytes and whole heart homogenates, fibroblasts had the highest specific activity.

\section{Discussion}

Our results showed that cultured cardiac fibroblasts produce and secrete two different glucuronidated iodothyronine conjugates upon exposure to $\mathrm{T} 4$ or $\mathrm{T} 3$, whereas cultured cardiomyocytes do not or do so to a much lesser extent. These findings support our hypothesis that cardiac fibroblasts are equipped to fulfil a potential role in local thyroid hormone metabolism in the heart.

The results from our analyses indicate that the watersoluble iodothyronine metabolites produced in vitro by cardiac fibroblasts are glucuronidated conjugates, and this conclusion is supported by our observation of the presence of UDP-glucuronyltransferase activities in these cells. To the best of our knowledge this is the first evidence of iodothyronine glucuronidation in the heart. Furthermore, our fibroblast cultures have no outer ring deiodinating activity, as judged from the absence of the appearance of free iodide in the culture medium upon exposure to phenolic (outer) ring ${ }^{125}$ I-labeled T4 or T3. Moreover, in our hands, cardiac fibroblasts from neonatal rats did not show a D1 activity. Inner ring deiodination can be conferred both by D1 and D3. However, the expression of D3 is most prominent in placenta and fetal tissues, declining rapidly with gestational age and after birth (Richard et al. 1998, Bates et al. 1999, Hernández et al. 1999). Indeed, in adult rat hearts, D3 activity is low to undetectable (Schiel et al. 2001). We therefore concluded that the glucuronidated conjugates produced by cardiac fibroblasts do not constitute deiodinated metabolites derived from $\mathrm{T} 4$ and $\mathrm{T} 3$, and that they most likely represent $\mathrm{T} 4$ glucuronide and T3 glucuronide respectively.

The analytical methods we used (i.e. acid hydrolysis and enzyme digestion) have also been employed by others to distinguish between sulfated and glucuronidated iodothyronine conjugates (Mol \& Visser 1985, Finnson \& Eales 1996). The conjugates produced upon $\mathrm{T} 4$ and $\mathrm{T} 3$ exposure behaved differently in our analyses, and this again indicated that our cultured cardiac fibroblasts indeed produced two different metabolites from the two iodothyronines. We also observed, initially to our surprise, that $\mathrm{T} 4$ glucuronide produced in vitro by fibroblasts was sensitive to acid hydrolysis, a result that was replicated for a T4 glucuronide synthesized from T4 using rat liver microsomes. Thus, an unknown conjugate that is sensitive to acid hydrolysis is not necessarily a sulfate, and we feel that the results from acid hydrolysis analyses should be interpreted cautiously.

In general, conjugation pathways such as glucuronidation are associated with detoxification processes in liver and bile excretion. The UDP-glucuronyltransferases (UDPGTs) constitute a family of isozymes. It has been demonstrated that, in rat liver microsomes, $\mathrm{T} 4$ and $\mathrm{rT} 3$ are the preferred substrates for phenol-UDPGT, whereas T3 is preferentially glucuronated by androsterone-UDPGT (Beetstra et al. 1991, Visser et al. 1993a,b,c). It remains to 
be established which UDPGT isozymes are responsible for T4 and T3 glucuronidation in cardiac fibroblasts. Our results suggested that a phenol-UDPGT is involved in T4 glucuronidation in fibroblasts. However, although cardiomyocytes possess a considerable phenol-UDPGT activity, they did not secrete conjugated iodothyronines in the culture medium. This would suggest that, in cardiomyocytes, phenol-UDPGT is not the major enzyme for thyroid hormone glucuronidation.

The appearance of glucuronidated thyroid hormone metabolites in the culture medium, as we observed in our cardiac fibroblast cultures, is the net result of a pathway consisting of an uptake and extrusion step and a glucuronidating mechanism, the latter almost certainly being a UDPGT activity. Although there are only a few experimental data on transport processes of iodothyronines in fibroblasts, it has been shown that fibroblasts possess temperature- and energy-dependent mechanisms for the uptake and extrusion of thyroid hormones (Docter et al. 1987, Benvenga \& Robbins 1990, Ribeiro et al. 1996). It is interesting to note that cultured fibroblasts and rat ventriculocytes possess a verapamil-sensitive thyroid hormone extrusion mechanism, possibly P-glycoprotein, a member of the multi-drug resistance protein family (MRP) (Ribeiro et al. 1996, Cavalieri et al. 1999). MRP glycoproteins have been reported to transport anionic conjugates (Keppler et al. 1999), and we will investigate whether these transporters are involved in the proteinmediated secretion of glucuronidated iodothyronines.

Experimental data on the cellular uptake of iodothyronines in cardiomyocytes are very scarce. Our previous results have shown that cardiomyocytes possess a temperature- and energy-dependent uptake mechanism for T3 (Everts et al. 1996, van der Putten et al. 2001, Verhoeven et al. 2001) and possibly also for T4 (van der Putten et al. 2001). In one of these studies (Verhoeven et al. 2001), a direct comparison between T3 uptake in fibroblasts and cardiomyocytes showed that T3 uptake (expressed per $\mu \mathrm{g}$ protein) was at least tenfold higher in the cardiomyocyte. The absence of glucuronated thyroid hormones in the cardiomyocyte culture medium is thus probably not due to negligible uptake of native hormones from the incubation medium.

It has been tentatively suggested that, e.g. during fetal development, in non-thyroidal illness or during treatment with outer ring deiodinating inhibitors, T4 and T3 sulfates are stored as inactive conjugates from which rapid mobilization of active hormone by sulfatase activity can occur (Visser 1996). A similar potential role in the inactivation and storage of hormone can be envisaged for glucuronidation of iodothyronines by cardiac fibroblasts. T3 sulfate, but not $\mathrm{T} 4$ sulfate, was sensitive to digestion by sulfatase; the resistance of T4 sulfate to sulfatase activity was probably due to steric hindrance of the two iodide atoms on the phenolic ring. In contrast, T3 glucuronide and T4 glucuronide were both deconjugated by $\beta$-glucuronidase.
Thus, glucuronidation of T3 as well as T4 is reversible, and this could be a mechanism for storing thyroid hormones. $\beta$-Glucuronidase activities have been amply demonstrated in lysosomal fractions derived from mammalian heart (Johnson et al. 1986, Ambrosio et al. 1990), and it would be interesting to investigate whether these activities are indeed located in cardiomyocytes and whether these cells possess a mechanism for the uptake of glucuronidated iodothyronines.

Others have shown that fibroblasts are involved in mediating the trophic response of the neonatal rat heart to angiotensin II, probably by releasing transforming growth factor- $\beta$ (Kim et al. 1995, Lee et al. 1995), and the secretory response of the intestine to inflammation by releasing prostaglandins (Berschneider \& Powell 1992, Kandil et al. 1994). We are currently investigating whether cardiac fibroblasts fulfil a similar role in local thyroid hormone action in the heart, using animal models of experimentally induced hyper- and hypothyroidism.

\section{Acknowledgements}

The authors are grateful to Pieter Looijmans and Miranda Niessen for competent analytical assistance and to Brian Joosten, Hans van Toor and Ellen Kaptein for expert technical support. The study was supported in part by The Netherlands Heart Foundation (NHS, The Hague, The Netherlands) (grant 96.175) and The Netherlands Organisation for Scientific Research (NWO, The Hague, The Netherlands) (grant 15.17.039).

\section{References}

Agocha AE \& Eghbali-Webb M 1997 A simple method for preparation of cultured cardiac fibroblasts from adult human ventricular tissue. Molecular and Cellular Biochemistry 172 195-198.

Ambrosio G, Pellegrino A, Cappelli-Bigazzi M, Perrone-Filardi P, Vallone C, Lepore S, Chiariello M \& Chiariello L 1990 Paradoxical effects of cardiac arrest by multidose potassium cardioplegia on myocardial lysosome integrity and phospholipid content. Journal of Surgical Research 49 132-137.

Bates JM, St Germain DL \& Galton VA 1999 Expression profiles of the three iodothyronine deiodinases, D1, D2 and D3, in the developing rat. Endocrinology 140 844-851.

Beetstra JB, van Engelen JGM, Karels P, van der Hoek HJ, de Jong M, Docter R, Krenning EP, Hennemann G, Brouwer A \& Visser TJ 1991 Thyroxine and 3,3',5-triiodothyronine are glucuronidated in rat liver by different uridine diphosphate-glucuronyltransferases. Endocrinology 128 741-746.

Benvenga S \& Robbins J 1990 Enhancement of thyroxine entry into low density lipoprotein (LDL) receptor-competent fibroblasts by LDL: an additional mode of entry of thyroxine into cells. Endocrinology 126 933-941.

Benvenga S \& Robbins J 1998 Thyroid hormone efflux from monolayer cultures of human fibroblasts and hepatocytes. Effect of lipoproteins and other thyroxine transport proteins. Endocrinology 139 4311-4318.

Berschneider HM \& Powell DW 1992 Fibroblasts modulate intestinal secretory responses to inflammatory mediators. Journal of Clinical Investigation $89484-489$. 
van Birgelen APJM, Visser TJ, Kaptein E, Kodavanti PRS, Derr-Yellin EC, DeVito MJ \& Birnbaum LS 1997 Synergistic effects on thyroid hormone metabolism in female Sprague Dawley rats after subchronic exposure to mixtures of PCDDs, PCDFs, and PCBs. Organohalogen Compounds 34 370-375.

Bonnin CM, Sparrow MP \& Taylor RR 1983 Increased protein synthesis and degradation in the dog heart during thyroxine administration. Journal of Molecular and Cellular Cardiology 15 $245-250$.

Cavalieri RR, Simeoni LA, Park SW, Baxter JD, Scharschmidt BF, Ribeiro RCJ \& Lomri N 1999 Thyroid hormone export in rat FRTL-5 thyroid cells and mouse NIH-3T3 cells is carriermediated, verapamil-sensitive and stereospecific. Endocrinology 140 4948-4954.

Dillmann WH 1990 Biochemical basis of thyroid hormone action in the heart. American Journal of Medicine 88 626-630.

Docter R, Krenning EP, Bernard HF \& Hennemann G 1987 Active transport of iodothyronines into human cultured fibroblasts. Journal of Clinical Endocrinology and Metabolism 65 624-628.

van Doorn J, Roelfsema F \& van der Heide D 1985 Concentrations of thyroxine and 3,5, ' $^{\prime}$-triiodothyronine at 34 different sites in euthyroid rats as determined by an isotopic equilibrium technique. Endocrinology 117 1201-1208.

Edgren J, von Knorring J, Lindy S \& Turto H 1976 Heart volume and myocardial connective tissue during development and regression of thyroxine-induced cardiac hypertrophy in rats. Acta Physiologica Scandinavica 97 514-518.

Everts ME, Verhoeven FA, Bezstarosti K, Moerings EPCA, Hennemann G, Visser TJ \& Lamers JMJ 1996 Uptake of thyroid hormones in neonatal rat cardiac myocytes. Endocrinology 137 4235-4242.

Finnson KW \& Eales JG 1996 Identification of thyroid hormone conjugates produced by isolated hepatocytes and excreted in bile of rainbow trout, Oncorhynchus mykiss. General and Comparative Endocrinology 101 145-154.

Hernández A, Lyon GJ, Schneider MJ \& St Germain DL 1999 Isolation and characterization of the mouse gene for the type 3 iodothyronine deiodinase. Endocrinology 140 124-130.

Horowitz B, Hensley CB, Quintero M, Azuma KK, Putnam D \& McDonough AA 1990 Differential regulation of Na,K-ATPase $\alpha 1$, $\alpha 2$, and $\beta$ subunit mRNA and protein levels by thyroid hormone. Journal of Biological Chemistry $26514308-14314$.

Johnson WG, Hong JL \& Knights SM 1986 Variation in ten lysosomal hydrolase enzyme activities in inbred mouse strains. Biochemical Genetics 24 891-909.

Kandil HM, Berschneider HM \& Argenzio RA 1994 Tumour necrosis factor $\alpha$ changes porcine intestinal ion transport through a paracrine mechanism involving prostaglandins. Gut 35 934-940.

Keppler D, Cui Y, König J, Leier I \& Nies A 1999 Export pumps for anionic conjugates encoded by MRP genes. Advances in Enzyme Regulation 39 237-246.

Kessler-Icekson G 1988 Effect of triiodothyronine on cultured neonatal rat heart cells: beating rate, myosin subunits and CK-isozymes. Journal of Molecular and Cellular Cardiology 20 649-656.

Kim NN, Villarreal FJ, Printz MP, Lee AA \& Dillman WH 1995 Trophic effects of angiotensin II on neonatal rat cardiac myocytes are mediated by cardiac fibroblasts. American Journal of Physiology 269 E426-E437.

Kim S, Hamaguchi A, Shinkawa T, Kato Y, Tsuchiya N, Miura K, Ohta K \& Iwao H 1996 Molecular effects of M17055, furosemide and thiazide on cardiac hypertrophy of spontaneously hypertensive rats. Journal of Pharmacology and Experimental Therapeutics 279 983-990.

Klein LE, Sigel AV, Douglas JA \& Eghbali-Webb M 1996 Upregulation of collagen type I gene expression in the ventricular myocardium of thyroidectomized male and female rats. Journal of Molecular and Cellular Cardiology 28 33-42.
Lee AA, Dillmann WH, McCulloch AD \& Villarreal FJ 1995 Angiotensin II stimulates the autocrine production of transforming growth factor- $\beta 1$ in adult rat cardiac fibroblasts. Journal of Molecular and Cellular Cardiology 27 2347-2357.

Lowry OH, Rosebrough NJ, Farr AL \& Randall RJ 1951 Protein measurement with the Folin phenol reagent. Journal of Biological Chemistry 193 265-275.

Mixson AJ, Hauser P, Tennyson G, Renault JC, Bodenner DL \& Weintraub BD 1993 Differential expression of mutant and normal beta $\mathrm{T} 3$ receptor alleles in kindreds with generalized resistance to thyroid hormones. Journal of Clinical Investigation 91 2296-2300.

Miyazaki T, Kanou Y, Murata Y, Ohmori S, Niwa T, Maeda K, Yamamura H \& Seo H 1996a Molecular cloning of a novel thyroid hormone-responsive gene, ZAKI-4, in human skin fibroblasts. Journal of Biological Chemistry 271 14567-14571.

Miyazaki T, Murata Y, Ohmori S, Niwa T, Maeda K \& Seo H $1996 b$ Molecular cloning of rat ZAKI-4 gene. Environmental Medicine $\mathbf{4 0}$ $13-16$.

Mol JA \& Visser TJ 1985 Synthesis and some properties of sulfate esters and sulfamates of iodothyronines. Endocrinology 117 1-7.

Muller A, Zuidwijk MJ, Simonides WS \& van Hardeveld C 1997 Modulation of SERCA2 expression by thyroid hormone and norepinephrine in cardiocytes: role of contractility. American Journal of Physiology 272 H1876-H1885.

Nair KG, Cutilletta AF, Zak R, Koide T \& Rabinowitz M 1968 Biochemical correlates of cardiac hypertrophy. Circulation Research 23 451-462.

van der Putten HHAGM, Joosten BJLJ, Klaren PHM \& Everts ME 2001 Characterization of uptake and compartmentalization of 3,5,3'-tri-iodothyronine in cultured neonatal rat cardiomyocytes. Journal of Endocrinology 171 183-192.

Ribeiro RCJ, Cavalieri RR, Lomri N, Rahmaoui CM, Baxter JD \& Scharschmidt BF 1996 Thyroid hormone export regulates cellular hormone content and response. Journal of Biological Chemistry 271 17147-17151.

Richard K, Hume R, Kaptein E, Sanders JP, van Toor H, de Herder WW, den Hollander JC, Krenning EP \& Visser TJ 1998 Ontogeny of iodothyronine deiodinases in human liver. Journal of Clinical Endocrinology and Metabolism 83 2868-2874.

Rohrer D \& Dillmann WH 1988 Thyroid hormone markedly increases the mRNA coding for sarcoplasmic reticulum $\mathrm{Ca}^{2+}$-ATPase in the rat heart. Journal of Biological Chemistry 263 6941-6944

Schiel A, Simonides W, van Hardeveld C, Wassen F, Kuiper G, Visser T, ZandiehDoulabi B, Bakker O \& Wiersinga W 2001 Differential regulation of type 1 and type 3 deiodinase activity in ventricular tissue during pathological hypertrophy. Proceedings of the 73rd Annual Meeting of the American Thyroid Association, p 262 .

Sterling K \& Brenner MA 1966 Free thyroxine in human serum: simplified measurement with the aid of magnesium precipitation. Journal of Clinical Investigation 45 153-163.

Verhoeven FA, Moerings EPCM, Lamers JMJ, Hennemann G, Visser TJ \& Everts ME 2001 Inhibitory effects of calcium channel blockers on thyroid hormone uptake in neonatal rat cardiomyocytes. American Journal of Physiology. Heart and Circulatory Physiology 281 H1985-H1991.

Visser TJ 1996 Pathways of thyroid hormone metabolism. Acta Medica Austriaca 23 10-16.

Visser TJ, Kaptein E, Gijzel AL, de Herder WW, Ebner T \& Burchell B 1993a Glucuronidation of thyroid hormone by human bilirubin and phenol UDP-glucuronyltransferase isoenzymes. FEBS Letters 324 358-360.

Visser TJ, Kaptein E, van Raaij JAGM, Tjong Tjin Joe C, Ebner T \& Burchell B $1993 b$ Multiple UDP-glucuronyltransferases for the glucuronidation of thyroid hormone with preference for 3,3', $5^{\prime}$-triiodothyronine (reverse T3). FEBS Letters 315 65-68. 
Visser TJ, Kaptein E, van Toor H, van Raaij JAGM, van den Berg KJ, Tjong Tjin Joe C, van Engelen JGM \& Brouwer A 1993c Glucuronidation of thyroid hormone in rat liver: effects of in vivo treatment with microsomal enzyme inducers and in vitro assay conditions. Endocrinology 133 2177-2186.

Yao J \& Eghbali M 1992a Decreased collagen gene expression and absence of fibrosis in thyroid hormone-induced myocardial hypertrophy. Circulation Research 71 831-839.
Yao J \& Eghbali M $1992 b$ Decreased collagen mRNA and regression of cardiac fibrosis in the ventricular myocardium of the tight skin mouse following thyroid hormone treatment. Cardiovascular Research 26 603-607.

Received 31 December 2001

Accepted 19 March 2002 